\title{
GLAD!
}

Revue sur le langage, le genre, les sexualités

11 | 2021

Archives, genre, sexualités, discours

\section{Déculonisons les archives}

Desculonizando os arquivos

\section{Pensées Sauvages}

\section{(2) OpenEdition}

Journals

Édition électronique

URL : https://journals.openedition.org/glad/3324

DOI : 10.4000/glad.3324

ISSN : 2551-0819

Éditeur

Association GSL

\section{Référence électronique}

Pensées Sauvages, « Déculonisons les archives », GLAD! [En ligne], 11 | 2021, mis en ligne le 20 décembre 2021, consulté le 29 janvier 2022. URL : http://journals.openedition.org/glad/3324 ; DOI : https://doi.org/10.4000/glad.3324

Ce document a été généré automatiquement le 29 janvier 2022.

\section{(c) (i) (9)}

La revue GLAD! est mise à disposition selon les termes de la Licence Creative Commons Attribution Pas d'Utilisation Commerciale - Pas de Modification 4.0 International. 


\title{
Déculonisons les archives
}

\author{
Desculonizando os arquivos
}

\section{Pensées Sauvages}

Cette bande dessinée est le résultat d'une recherche d'archives sur les violences policières contre la population LGBT à Marseille dans les années 1930. Lors d'une recherche aux archives municipales, le mot-clef « travesti » nous a renvoyé au dossier «Opium Saisies Arrestations et Rapports », provenant de la Préfecture de Police de Marseille. Dans la description, il disait contenir« deux photos de Narboni dite l'Algérienne (1929) ». Ce rapport a été émis par la Police centrale de Marseille sur la demande du Préfet des Bouches-du-Rhône concernant la "pratique d'actes d'homosexualité » et le "trafic des stupéfiants» à Marseille. A travers la bande dessinée, on a laissé de la place à l'imaginaire dans cette analyse d'archive, afin de ne pas figer nos catégories d'analyse sur un contexte où elles auraient été anachroniques. Le dessin nous a permis d'ouvrir une brèche dans les représentations hétéronormatives de la police pour entrevoir les possibilités d'autodéterminations des personnes qui ont été incriminées pour ne pas correspondre à leur morale. Cette recherche résulte du désir de retracer l'histoire des personnes dissidentes du genre à Marseille, en soulevant la problématique d'utiliser des sources fournies par un organe répressif. 


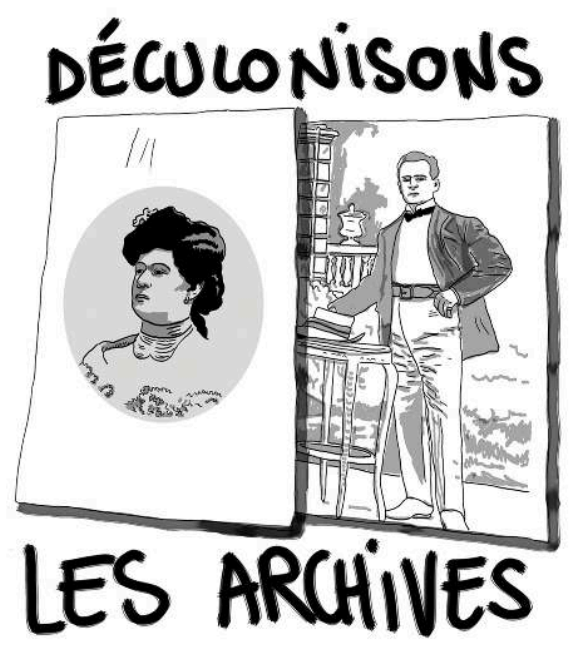

Qui était Narboni ?

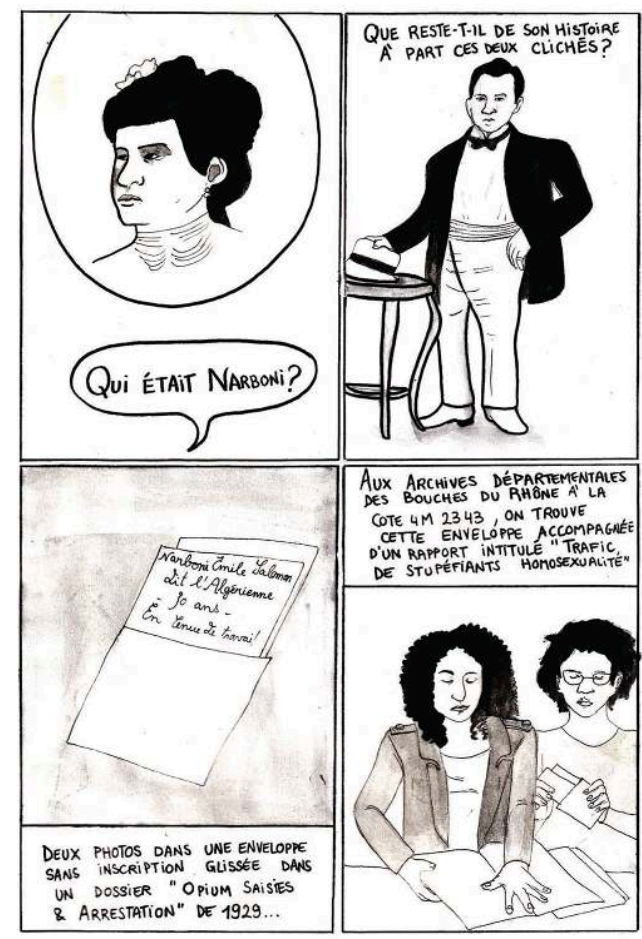


"L'Algérienne »

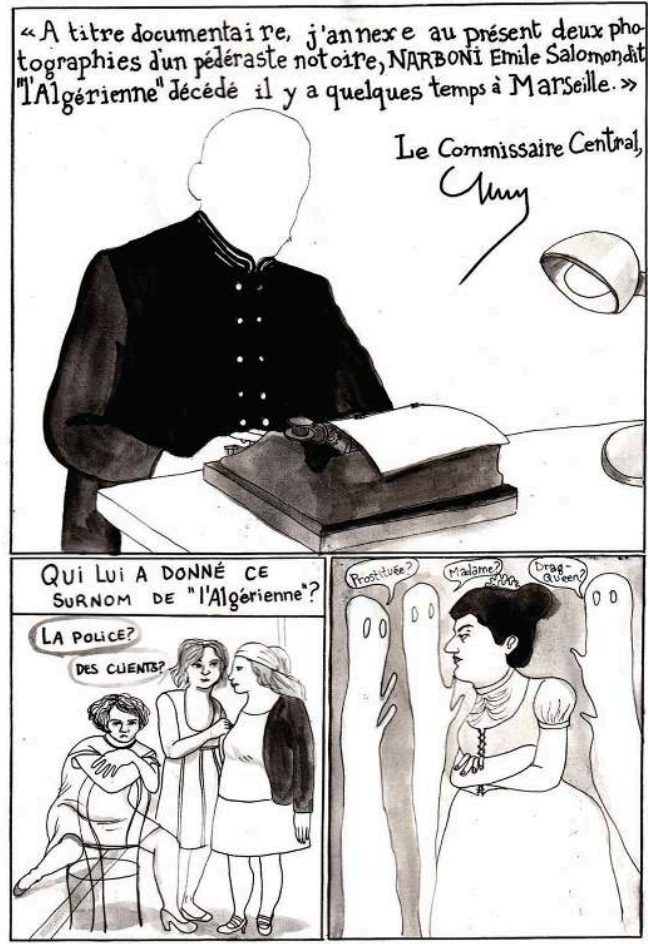

Qui étaient ces guerrières ?

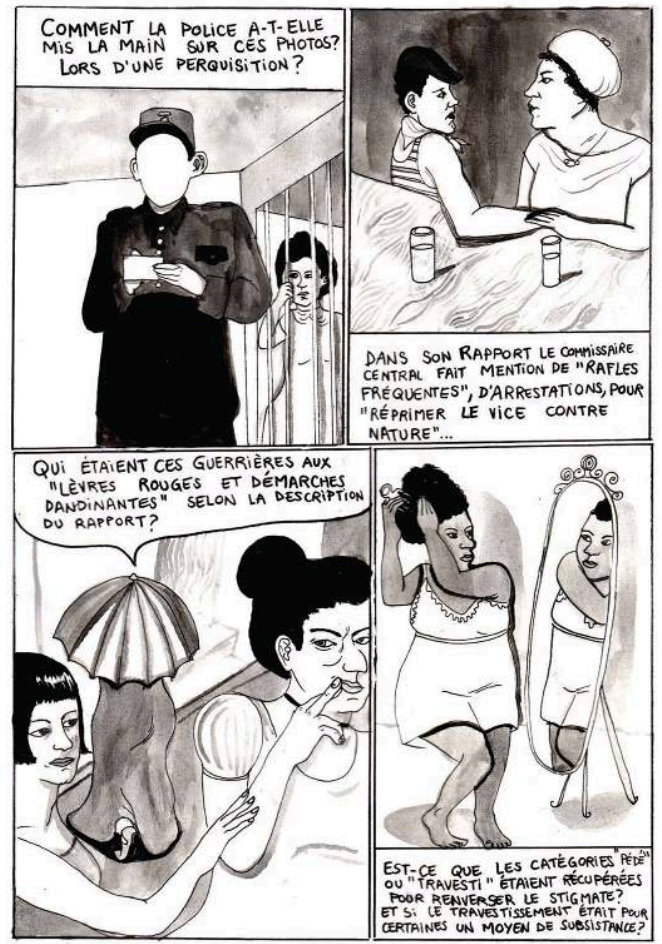




\section{Entre fétichisme et pathologisation}

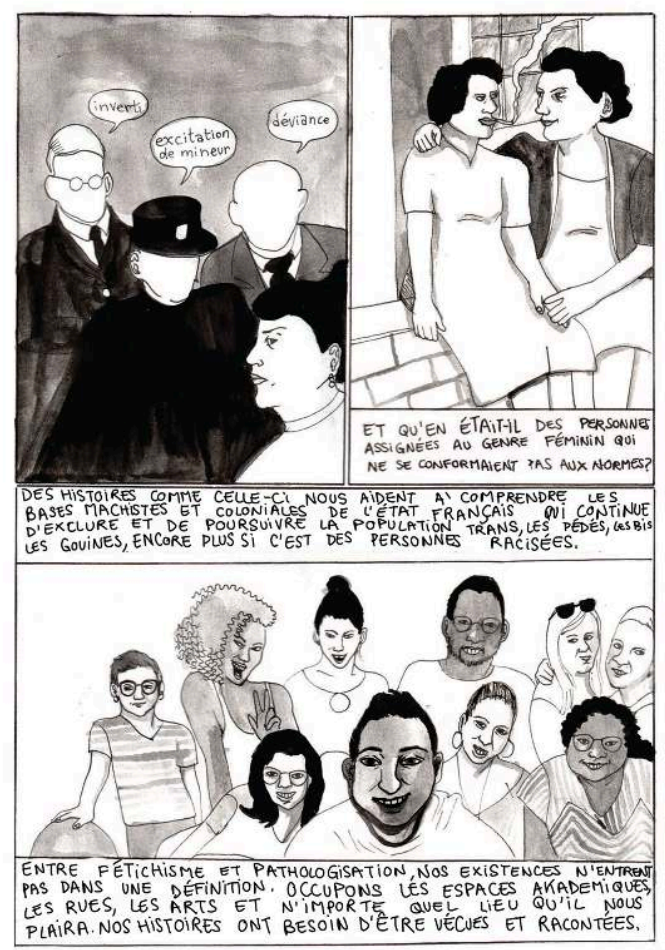

\section{RÉSUMÉS}

Cette bande dessinée est le résultat d'une recherche d'archives sur les violences policières contre la population LGBT à Marseille dans les années 1930.

Esse quadrinho é o resultado de uma pesquisa de arquivos sobre a violência policial contra a população LGBT em Marselha nos anos 1930. Durante uma pesquisa nos arquivos municipais, a palavra-chave "travesti" nos levou a conhecer o arquivo "Opium apreensões, arrestações e relaótorios", emanando da Prefeitura de Policia de Marselha. Na descripção, estão mencionadas "duas fotos de Narboni, chamada a Algerina (1929)". Esse relatório foi emetido pela policia central de Marselha, depois do pedido do prefeito da região, relativamente a "pratica de atos de homosexualismo" e o "trafico de drogas" na cidade. Pelo meio do quadrinho, a gente deixou espaço ao imaginario nessa analise de arquivos, com o objetivo de não fixar nossas categorias de analise em um contexto onde elas teriam sido anacronicas. o desenho nos permitiu abrir uma brecha nas representações heteronormativas da policia para vislumbrar as possibilidades de autodeterminações das pessoas que foram incriminadas por não corresponder a sua moral. Essa pesquisa resulta do desejo de rastrear a historia de pessoas dissidentes do gênero em Marselha, levantando a problemática de usar fontes fornecidas por um orgão repressor. 
INDEX

Thèmes : Créations

Mots-clés : travesti, algérienne, Marseille, répression policière, bande dessinée

Palavras-chave : travesti, algerina, Marselha, repressão policial, historia em quadrinhos

\section{AUTEUR}

\section{PENSÉES SAUVAGES}

Collectif de traductions et d'expérimentations féministes, sous des formes chantées, dessinées, filmées ou encore écrites. penseessauvages.net 